\title{
Exacerbation of dementia after the earthquake and tsunami in Japan
}

\author{
Katsutoshi Furukawa $\cdot$ Mari Ootsuki $\cdot$ \\ Manabu Kodama $\cdot$ Hiroyuki Arai
}

Received: 16 August 2011/Accepted: 13 November 2011/Published online: 30 November 2011

(C) Springer-Verlag 2011

\section{Dear Sir,}

On Friday, March 11, 2011, a magnitude 9.0 earthquake hit Japan, which was followed by enormous tsunamis that caused numerous casualties and serious damage in the coastal cities [1]. After the disaster, many elderly people including patients with dementia were evacuated to asylums such as gymnasiums and halls because their houses were destroyed. Many of the patients visited our clinic after evacuation, and most of them got significantly worse with their dementia symptoms including behavioral and psychological symptoms of dementia (BPSD). We here examined changes in cognitive functions and BPSD with minimental state examination (MMSE) and neuropsychiatric inventory-questionnaire (NPI-Q), respectively, in patients with Alzheimer's disease after the earthquake.

We analyzed three groups including subjects who did not suffer from the disaster (group $1, \mathrm{M} / \mathrm{F}=9 / 11$, age $74.3 \pm 8.3$ ), subjects who had experienced the disaster but did not stay at an evacuation site (group 2, M/F $=9 / 9$, age $75.6 \pm 7.8$ ), and subjects who were forced to stay at an evacuation site (group 3, $\mathrm{M} / \mathrm{F}=8 / 9$, age $77.8 \pm 8.5$ ). We compared the altered values (after-before) of each test in the three groups. Both groups 2 and 3 showed a decline in MMSE compared to group 1 although a significant difference was observed only between "group 1 and 2" and "group 1 and 3". Concerning the NPI-Q both group 2 and 3

K. Furukawa $(\varangle) \cdot$ M. Ootsuki $\cdot$ H. Arai

Department of Geriatrics and Gerontology, Division of Brain

Sciences, Institute of Development, Aging and Cancer, Tohoku

University, 4-1 Seiryo-cho Aobaku, Sendai 980-8575, Japan

e-mail: kfurukawa-ns@umin.ac.jp

M. Kodama

Division of Psychiatry, Kodama Hospital, Ishinomaki, Japan exhibited exacerbation of BPSD and the significant difference was observed between "group 1 and 2", "group 1 and 3" and "group 2 and 3" (Fig. 1).

Disasters such as earthquakes, tsunamis, hurricanes, and tornados must be extremely stressful to elderly people. On the other hand, to change their circumstances to inferior conditions such as evacuation sites should affect their mental and cognitive condition more severely [2]. Nobody likes to live together with many other people in a big hall with people having poor hygiene. Not only physical but also mental care to the elderly who suffered from the disaster is now needed.
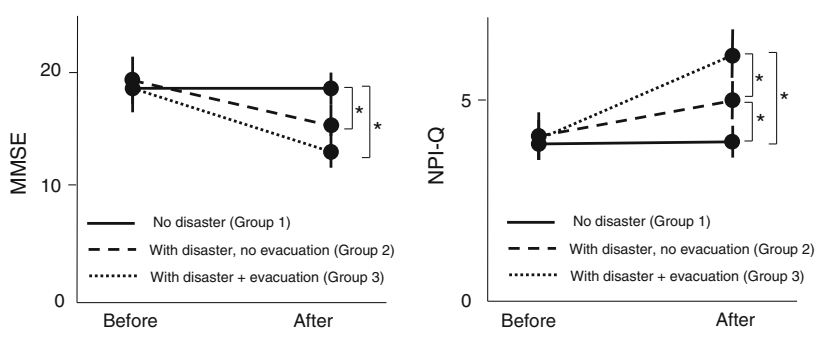

Fig. 1 Alterations of MMSE and NPI-Q after the earthquake and tsunami in patients with Alzheimer's disease. Changed values of each test between before and after the disaster were statistically analyzed. Values indicate mean \pm SE. $* p<0.05$

Conflict of interest The authors have no conflicts of interest to declare.

\section{References}

1. Furukawa K, Arai H (2011) An earthquake in Japan. Lancet 377:1652

2. Cloyd E, Dyer CB (2010) Catastrophic events and older adults. Crit Care Nurs Clin North Am. 22:501-513 